\title{
Study on Measuring Methods of Real Estate Speculative Bubble
}

\author{
Yifei Lai ${ }^{1}$, Huawei $\mathrm{Xu}^{1}$, Junping $\mathrm{Jia}^{1}$ \\ ${ }^{1}$ School of Economics and Management, WuhanUniversity, Wuhan, Hubei, China. \\ Email: lyf37319@163.Com
}

Received December $18^{\text {th }}, 2008$; revised January $14^{\text {th }}, 2009$; accepted February $5^{\text {th }}, 2009$.

\begin{abstract}
The paper analyses the causes of the bubble of the real estate, then elaborates real estate bubble theory based on speculation. This paper establishes a regression model of real estate's price with relevant economic variables, and builds the econometric model to measure real estate's speculative bubble. In application of the model for empirical research on real estate's speculative bubble of Chongqing, the paper concludes that globally there is no bubble in Chongqing (but on the edge of bubble). Finally, by analyzing the common points about the existence of bubble, the paper indicates that real estate's investment and macro-economic indexes are disjointed, and thus the investment is excessive, which can in turn corroborate the conclusions obtained by the measuring model.
\end{abstract}

Keywords: real estate, speculative bubble, measuring model of speculative bubble, overinvestment

\section{Introduction}

At present, China is under the pressure of high inflation, and real estate price soared quickly. From 2005 to 2007, the government adopted a series of macro-control policies, for example, in March 2005, "country's 8 items" came out, so that the regulation of real estate was boosted to a high degree of polity; in April 2006, mortgage interest rate rose again; in May, "country's 6 items" came out, then waged a new round of large-scale control; at the same period, China begun to impose tax on second-hand estate's sales; in July, China begun to impose personal income tax of transferring second-hand estate; in September, down payment rose. However, the real estate industry continues to show strong-run tendency, real estate price remains high. The real estate industry is highly relevant to many other industries, and its positive run can promote the development of other industries. Otherwise, if the real estate industry goes against the Law of value of market, its price separates from the market base but keeps irrational growth, the bubble is inevitable, and when the bubble has expanded to a certain degree to leak, then the financial system will bear the brunt, and even the national economy will experience turbulence. In 1997, the breakdown of real estate speculative bubble plunged Japan into stagnant economic downturn. Thus, it is of great significance to measure the speculative bubble of the current real estate market and identify the over-investment. Chongqing's real estate was selected as an example to measure its speculative bubble applying the proposed methods.

\section{The Theory and Measuring Model}

\subsection{Real Estate Bubble Based on Speculative Theory}

According to the reasons of real estate bubble, under the effect of consumer expectation, there are many positive feedback effects, namely, investors dealing according to the tendency of past asset price, not to the real price. Thus, we can consider, positive feedback deal determines the change of future demand in real estate market, and then the expectation of future real estate price in market is determined by the expectation of future change of demand. Firstly, when the increasing rate of real estate price exceeds credit loan rate, the real estate price speculation comes out. At this time, investors achieve speculative aim by changing hand to get the price difference; secondly, there is time interval between buying and selling, which provides speculative possibility. At last, because of the imperfection of market mechanism and information asymmetries, the price arbitrage action of speculators will result in the achievement of expectation.

\subsection{The Measuring Model of Real Estate Speculative Bubble}

In terms of positive feedback mechanism, real estate price at current period will be affected by past several real estate price. Considering that speculations are general short-term price arbitrage action by selling real estate, because speculators are not aiming to achieve the steady long-term profit in the future, e.g., earning rents after buying estate.

Let $h_{t}$ figures real increasing rate of real estate price at period $t$, which is achieved after eliminating the growth 
part of real estate price due to the increase of income $Y_{t}$. According to the analysis above, the real increase of future real estate price is only determined by the price expectation of economic subjects in terms of the price at current period, so we establish the econometric model below:

$$
h_{t}=\theta_{1} h_{t-1}+\theta_{2} h_{t-2}+\varepsilon_{t}
$$

$h_{t-1}, h_{t-2}$ separately figures the real rate of growth lagging one period and two periods, here at most two lag periods are discussed. $\theta_{1}$ figures the effect of the increasing rate of real estate price lagging one period to the real estate price at current period, reflecting one-year economic subject's expectation of future real estate price tendency, so we define the coefficient $\theta_{1}$ to mainly reflect real estate speculative bubble. Because we mainly consider speculators' short-term (one year) speculative action, then when we consider economic subjects' expectation at short-term but over one year, $\theta_{2}$ is considered as the ancillary index to reflect how economic subjects' action affects the growth of real estate price after one year, $\varepsilon_{t}$ figures the unexpected shock at current period.

\section{Emprical Analysis}

\subsection{The Choice of Parameters}

According to the factors affecting real estate price, we choose one-year credit loan rate of commercial banks as mortgaged lending rate of real estate, disposable income of urban residents, real estate price. We adopt weighted processing the one-year credit loan due to its change in a year. The influence of inflation on disposable income is eliminated along with the years. The real estate price is available from the literature data. Credit loan rate of banks reflects the support degree of finance institutions to the development of real estate industry; it also reflects the attitude of government toward the development of real estate industry. Because there are mainly urban residents buying estate (especially speculating) in cities, so we choose the disposable income of urban residents to reflect residents' demand (or consumption ability) for real estate.

\subsection{The Establishment of Regression Equations}

In order to establish regression model between real estate price and other variables, and ensure that, under confidence level, other variables prominently affect real estate price, and variables in the equation do not have correlation each other, we choose Stepwise regression to establish equation. In the equation, $P_{t}$ (Price) means real estate price at current period, $I_{t}$ (Rate) means rate, $P_{t-1}$ (Lag price) figures real estate price lagging one period; $Y_{t}$ (Income) figures the disposable income of urban residents. Data is mainly from "Statistical Yearbook 2007 of Chongqing" and correlative years' statistical yearbooks of Chongqing. The model is the foundation of establishing real estate price speculative bubble measuring model, so the accuracy of equation's establishment is essential.
According to the analysis above, we establish regression equation below:

$$
\ln P_{t}=a_{0}+a_{1} \ln I_{t}+a_{2} \ln Y_{t}+a_{3} \ln P_{t-1}+\varepsilon
$$

The value of $\mathrm{p}$ that variables stay and kick out in the regression equation are separately set at 0.1 and 0.15 ,. In application of SAS 9.0 to do regression analysis, partial results of regression are shown below.

$$
\begin{aligned}
& \text { 1) Regression model } \\
& \ln P_{t}=1.131+0.126 \ln I_{t}+0.37 \ln Y_{t}+0.479 \ln P_{t-1}
\end{aligned}
$$

Through the analysis, we know that, under the confidence level of $10 \%$, variables all stay in the equation, and can be considered to produce significant affects on the change of real estate price

2) The model fitting effect

From analytical results, we know that, the value of fitting degree equals 0.9892 , and adjusted $R^{2}$ equals 0.9867 , so the model is available wholly.

\section{3) D-W test}

The value of D-W equals 1.649, which is between 1.54 and 2.46 , and indicates, under the confidence level of $5 \%$, we can refuse the assumption of the sequence correlation.

\subsection{The Measuring Model of Real Estate Speculation Bubble}

From (3), the formula below can be obtained,

$$
\begin{aligned}
& P_{t-1}=e^{1.131} I_{t-1}^{0.26} Y_{t-1}^{0.37} P_{t-2}^{0.479} \\
& P_{t}^{\prime}=\frac{P_{t}}{I_{t}^{0.131} Y_{t}^{0.37}}=e^{1.131} P_{t-1}^{0.479} \\
& \frac{P_{t}^{\prime}}{P_{t-1}^{\prime}}=\left(\frac{P_{t-1}}{P_{t-2}}\right)^{0.479}
\end{aligned}
$$

or

New $P_{t}^{\prime}$ sequence eliminates the rate and income affect of real estate price, so we can better investigate the bubble due to price speculation.

$$
h_{t}=\frac{P_{t}^{\prime}}{P_{t-1}^{\prime}}-1
$$

From (2),

$$
h_{t}=\left(\frac{P_{t-1}}{P_{t-2}}\right)^{0.479}-1
$$

According to the analysis above, $h_{t}$ means the real rate of real estate price at current period, so in terms of the formula $h_{t}=\theta_{1} h_{t-1}+\theta_{2} h_{t-2}+\varepsilon_{t}$ obtained from positive feedback mechanism, we can employ coefficient $\theta_{1}$ to measure (one year) the degree of speculative bubble.

\subsection{Econometric Model Measuring the Coeffi- cient of Price Bubble}

The tendency of real increasing rate of real estate price $h_{t}$ (HPRATE) can be obtained easily, in application of 

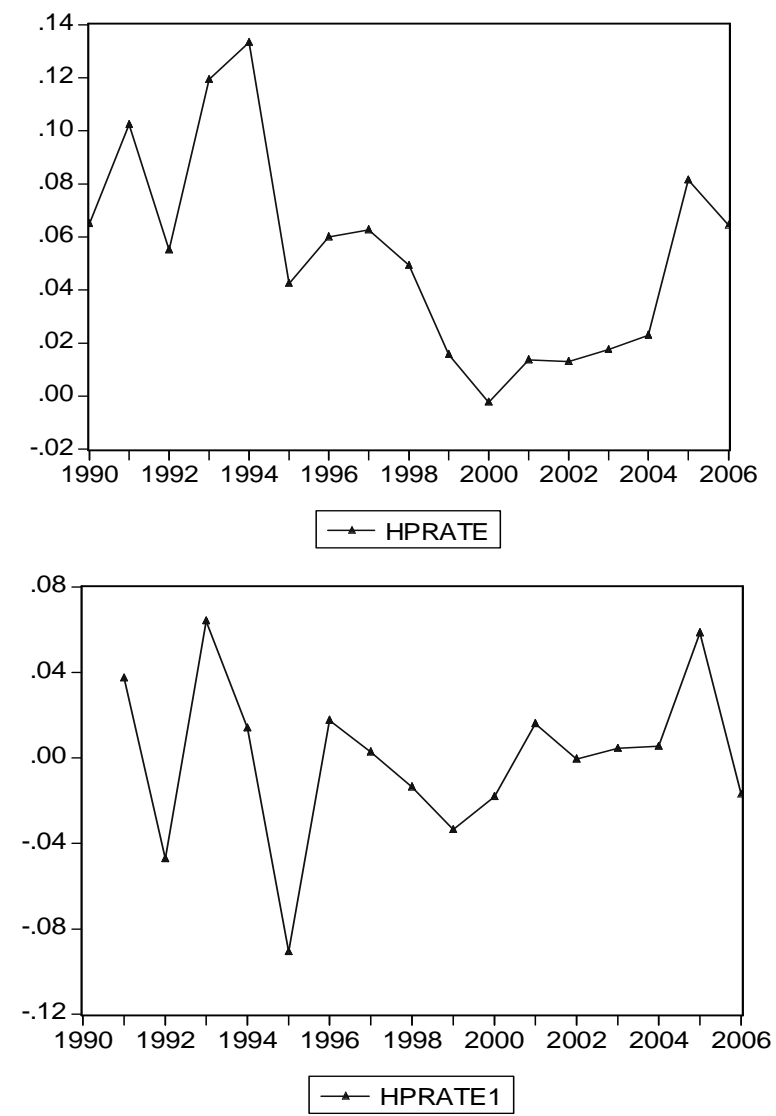

Figure 1. Trend of real increasing rate of real estate price $h_{t}$ (HPRATE) and first difference (HPRATE1) time series

Eviews5.0 to conduct time series analysis, co-integration test with HPRATE, we find that it is not integrative under the level, after first difference, this time series (HPRATE1) become a unit root series, and the trend chat of the two are shown as following.

From the trend chart of HPRATE1, we know that, real increasing rate of real estate price took on large fluctuation in 1995, and then it fell to normal level in 1996, this illustrated that there existed affective factors producing large shock to real estate price, we consider that there exists structure change. In fact, the investment of real estate in our country between 1992 and 1993 was exceeded, then in 1994, the government carried out macro-control of our economy, "City Real Estate Management Law" coming out, leading economy to practice soft landing. Considering the lag effect of macroeconomics policy, we set dummy variable PL to reflect the shock of policy.

Establish the following model:

$$
h_{t}=\theta_{1} h_{t-1}+\theta_{2} h_{t-2}+\beta P L+\varepsilon_{t}
$$

From the table above, we get the model below:

HPRATE $1=0.007-0.12 * \mathrm{PL}+[\mathrm{AR}(1)=-0.63$,

$\operatorname{MA}(1)=0.91$, BACKCAST $=1992]$
Table 1. Eviews analysis results

\begin{tabular}{ccccc}
\hline Variable & Coefficient & Std. Error & t-Statistic & Prob. \\
\hline C & 0.006593 & 0.008439 & 0.781300 & 0.4511 \\
PL & -0.116048 & 0.033162 & -3.499400 & 0.0050 \\
AR(1) & -0.631575 & 0.196634 & -3.211928 & 0.0083 \\
MA(1) & 0.910039 & 0.049313 & 18.45421 & 0.0000 \\
R-squared & 0.723529 & Durbin-Watson stat & 1.96375 \\
\hline
\end{tabular}

Obviously, the original model is:

$$
h_{t}=0.007-0.12 P L+0.37 h_{t-1}+0.63 h_{t-2}
$$

\subsection{Results Analysis}

From the results, we know that coefficient of real estate speculation $\theta_{1}$ equals 0.37 which is close to the international alertness line 0.4 , but it is not at bubble level; ancillary index $\theta_{2}$ equals 0.63 , which also reflects the expectation (over one year) of economic subject in certain extent images bubble degree. Coefficient of policy shock variable PL $\beta$ equals -0.12 , which reflects that the macroeconomics policy in 1994 well restrained real estate speculation. So we can have following conclusion:

The real estate industry in Chongqing is on the edge of bubble, but does not take on bubble, the macroeconomics policies in 1994 worked. This conclusion basically accords with the reality of Chongqing.

\subsection{Further Analysis of the Model Conclusion}

From the conclusion of the model, we know that our Chongqing is on the edge of bubble, but not has bubble, but why there generally exist "bubble intimidation theory", "bubble perdition theory". We support the conclusion of speculation measuring model analysis by analyzing the relation between real estate investment and macroeconomics variable. We choose real estate investment (REINV) and GDP of Chongqing, and also analyze the relation of real estate investment and disposable income (INCOME) of urban residents.

1) Co-integration test. Through ADF test, we find the real estate investment (REINV2), GDP (GDP2, urban residents' income (INCOME2) are all 2-order integration variables. Co-integration test uses M3 model and AIC principle to choose lag order. The lag order is 3 periods in co-integration test of REINV2 and GDP2, the value of AIC is 13.11743; the lag order is 3 periods in the co-integration of REINV2 and GDP2, the value of AIC is 15.84799. The results of Co-integration test are shown in Table 2.

2) Granger causality test. Because the three variables are all 2-order integration variables, we can directly use VAR model to conduct Granger causality test. We try to choose different orders to study the sensitivity of the test results, and the results are shown in Table 4. 
Table 2. REINV2 and INCOME2 Johansen co-integration test results

\begin{tabular}{|c|c|c|c|c|}
\hline Count of Co- integration Equations & Eiqenvalue & T-Statistic & $5 \%$ Critical Value & prob. $* *$ \\
\hline None & 0.376550 & 9.292334 & 15.49471 & 0.3390 \\
\hline At most one & 0.136708 & 2.205029 & 3.841466 & 0.1376 \\
\hline Count of Co-integration Equations & Eiqenvalue & Most Eiqenvalue Statistic & $5 \%$ Critical Value & prob.** \\
\hline none & 0.376550 & 7.087305 & 14.26460 & 0.4789 \\
\hline At most one & 0.136708 & 2.205029 & 3.841466 & 0.1376 \\
\hline
\end{tabular}

Table 3. REINV2 and GDP2 Johansen co-integration test results

\begin{tabular}{|c|c|c|c|c|}
\hline Count of Co-integration equations & Eiqenvalue & T-Statistic & $5 \%$ Critical Value & prob. $* *$ \\
\hline None & 0.395752 & 10.20828 & 15.49471 & 0.2651 \\
\hline At most one & 0.162037 & 2.651715 & 3.841466 & 0.1034 \\
\hline Count of Co-integration equations & Eiqenvalue & Most Eiqenvalue Statistic & $5 \%$ Critical Value & prob. $* *$ \\
\hline None & 0.395752 & 7.556565 & 14.26460 & 0.4256 \\
\hline At most one & 0.162037 & 2.651715 & 3.841466 & 0.1034 \\
\hline
\end{tabular}

Table 4. Two groups of variables' Granger causality test results

\begin{tabular}{llccccc}
\hline \multirow{2}{*}{ Variables } & \multirow{2}{*}{$H_{0}$ (Null Hypothesis) } & \multicolumn{4}{c}{ Probability } \\
\cline { 3 - 6 } & & Lag=1 & Lag=2 & Lag=3 & Lag=4 & Lag=5 \\
\hline \multirow{2}{*}{ REINV2-GDP2 } & GDP2 does not Granger Cause INVEST2 & 0.726 & 0.643 & 0.32 & 0.790 & 0.884 \\
\multirow{2}{*}{ REINV2-INCOME2 } & INVEST2 does not Granger Cause GDP2 & 0.074 & 0.109 & 0.016 & 0.137 & 0.413 \\
& INCOME2 does not Granger Cause INVEST2 & 0.777 & 0.997 & 0.258 & 0.540 & 0.312 \\
& INVEST2 does not Granger Cause INCOME2 & 0.0001 & 0.005 & 0.033 & 0.157 & 0.418 \\
\hline
\end{tabular}

From Table 3 and Table 4, we can get that under the confidence level of 0.1 , real estate investment, GDP and the income of urban residents do not have co-integration, which shows that real estate investment has been out of the track of macroeconomic development, and overinvestment appears.

Table 4 further shows that under the confidence level of 0.1 , real estate investment and GDP, income only have one-way causality. Real estate investment can promote the growth of GDP and strongly promote income growth in the short term, which once again indicates the existence of speculation which is short-term.

\section{Conclusions}

This paper empirically analyzes real estate speculative bubble of Chongqing after establishing bubble measuring model. The results indicate that Chongqing's real estate has not reached the bubble level, but is close to critical value. The paper also analyzes the opinions of bubble theory in the society, and empirical analysis pointes out that there is excessive investment of real estate, which separates from the growth of GDP and residents' income in Chongqing. The conclusion accordingly supports the empirical analysis results of speculative bubble measuring model.

Empirical analysis concludes that real estate of Chongqing is on the verge of bubble, which offers consultation for policymaker to work out corresponding measures.

In addition, through macroeconomics regulation, the government should scale down the investment of real estate to the normal level, coordinate with macroeco- nomics indexes of the region, to avoid excessive investment then to further induce expansion of bubble.

\section{REFERENCES}

[1] P. Wang, "Market efficiency and rationality in property investment," Journal of Real Estate Finance and Economics, 21(2): pp.185-200, 2000.

[2] C. Lizieri and S. Satchell, "Interacion between property and equity markets: An investigation of linkages in the UK 1972-1992," Journal of Real Estate Finance and Economics, 1997(15): pp.11-25, 1997.

[3] J. Abraham and P. H. Hendershott, "Bubbles in metropolitan housing markets," Housing Res, 1995(6): pp. 191-207, 1995.

[4] P. Bacon, F. Mac Cabe, and A. Murphy, "An economics assessment of recent house price developments," [M] Government of Ireland Publication, Dublin, 1998.

[5] J. Eatwell, M. Milgate, and P. Newman, "The new palgrave: A dictionary of economics," London Mac. Millan, Vol. 1, pp. 28.

[6] K. H. Kim and H. S. Seoung, "Speculation and price bubbles in the korean and japanese real estate markets," Journal of Real Estate Finance and Economics [J], 1993(6): pp. 73-86.

[7] K. H. Kim and H. S. Lee, "Real estate price bubble and price forecasts in Korea," Proceedings of 5th AsRES conference in Beijing, 2000.

[8] J. K. Zhou, "Financially support excessively and the real estate bubble," Beijing University Press, 2005.

[9] H. Y. Liu and H. Zhang, "Real estate and socio-economic," Tsinghua University Press, 2006.

(Edited by Vivian and Ann) 